\title{
O CONCEITO DE PRIMITIVIDADE
}

\section{Claude Lévi-Strauss}

\author{
Miguel Aparicio (D)
}

Universidade Federal do Oeste do Pará I Santarém - PA - Brasil

\author{
Texto originalmente publicado em Lévi-Strauss, C. 1968 \\ The concept of primitiveness, in Man the Hunter, \\ editado por Richard B. Lee e Irven DeVore, pp. 349-352. \\ New York: Aldine De Gruyter.
}


Como todos os conferencistas, fiquei profundamente impressionado com a riqueza, diversidade e qualidade dos novos materiais apresentados por colegas que recentemente retornaram do campo ${ }^{1}$. Esta é a primeira vez na minha vida que assisto a um simpósio com tantos nomes anteriormente desconhecidos para mim. Eu entendi o porquê assim que entrei na sala: a faixa etária mudou! É, de fato, reconfortante saber que a antropologia está em tão boas mãos e descobrir que está de novo de pé, depois de um período em que poderia haver um receio de que ela se tornaria nada mais do que uma tentativa de trabalhar para a melhoria da humanidade através dos estudos de aculturação. Não é que esta última empresa não tenha valor, mas a antropologia tem também outro papel, isto é, dar testemunho às futuras gerações da engenhosidade, diversidade e imaginação da nossa espécie - qualidades cuja evidência seria logo perdida para sempre.

Os problemas que discutimos são urgentes não só por causa da necessidade premente de estudar culturas em desaparecimento, mas também porque esses problemas ocupam uma posição especial no pensamento antropológico, tornando-se carregados de ambiguidade. Se eu tentar captar o rumo geral de nossa discussão até agora, pareceme que fomos confrontados com três diferentes níveis de ambiguidade. Nossa principal tarefa é encontrar o caminho para sair deles.

O primeiro nível de ambiguidade vem do fato de que um dos propósitos deste simpósio é trazer uma espécie de reabilitação das sociedades caçadoras e coletoras; nós não podemos as considerar como pertencentes a uma condição semianimal da humanidade. No entanto, ao mesmo tempo, eu percebi uma forte tentação de recorrer a estudos recentes de primatas - macacos e símios - ou até mesmo estudos de mamíferos menores, como roedores, para explicar, por exemplo, a existência de um instinto territorial em aborígenes australianos. O aparecimento dos magníficos estudos de DeVore torna a consideração de tais problemas ainda mais tentadora. No entanto, não devemos esquecer que a principal utilidade desses estudos de primatas é dupla: primeiro, eles nos permitem fazer hipóteses sobre formas antigas de culturas humanas incipientes - ou seja, o que aconteceu há cerca de um ou dois milhões de anos. Em segundo lugar, eles revelam fatos tão fundamentais que,

1 [Nota do tradutor]: Este texto é uma versão editada do discurso que Lévi-Strauss emitiu ao receber a Medalha e o Prêmio do Fundo Viking, no dia 8 de abril de 1966, no Centro de Educação Continuada da Universidade de Chicago, durante a realização do Simpósio "Man the Hunter". O Simpósio, organizado por Richard Lee e Irven DeVore, foi considerado um dos momentos mais significativos na trajetória da Ecologia Cultural, e contou com a participação de nomes expressivos da antropologia da época, tais como Julian Steward, George Peter Murdock e Marshall Sahlins. As apresentações do Simpósio, entre as quais consta o discurso de Lévi-Strauss, foram compiladas na coletânea de mesmo nome, editada por Lee e DeVore, publicada por Aldine De Gruyter em 1968. 
se são verdadeiros para os primatas, também o são para toda a humanidade. Eu não creio que possam ter uma relevância especial em relação a um certo tipo de sociedade: se eles se referem ao passado remoto ou ao presente, sua validade deve ser universal. Então, a primeira questão é que os caçadores-coletores, por mais diferentes que possam ser da nossa própria civilização, pertencem a um passado tão recente que há uma diferença muito maior entre eles e qualquer tipo de sociedade animal do que entre eles e as mais complexas sociedades humanas.

Certamente, não devemos tentar usar os atuais caçadores-coletores para reconstruir eventos e condições da pré-história da humanidade. Não afirmo que durante períodos pré-históricos não existissem pequenos bandos nômades comparáveis em tamanho e, talvez, em modo de vida ou em algumas atividades aos caçadores de hoje. Contudo, grupos pré-históricos como esses foram provavelmente, mesmo naquele tempo, "sobras" ou descendentes em declínio de culturas contemporâneas mais ricas. Por exemplo, foi sugerido durante este simpósio que a melhor comparação etnográfica para as culturas do Paleolítico Superior de Dordogne são as culturas dos índios da Costa Noroeste, grupos aqui excluídos da comparação com o argumento de que eles eram muito diferentes de outros caçadores-coletores. Devemos também recordar o comentário anterior, de Lathrap, neste simpósio, segundo o qual na América do Sul, e sem dúvida em muitos outros lugares, os caçadores-coletores não eram representativos de uma condição anterior da humanidade, sendo regressivos mais do que primitivos. Eu coloquei esta questão cerca de vinte anos atrás em relação aos Nambikwara (LéviStrauss 1963), inclusive tentei demonstrar isso, ao destacar que havia sintomas diagnósticos em uma sociedade regressiva que, por um lado, apontavam discrepâncias dentro da cultura e que, por outro lado, ao considerar uma de cada vez, estavam de acordo com o que vinha acontecendo em uma ou outra sociedade vizinha.

O segundo nível de ambiguidade tem a ver com a discrepância entre o modelo e a realidade empírica. Parece estranho para mim ter ouvido neste simpósio que, de repente, foi "descoberto" que as culturas primitivas são semelhantes à nossa na medida em que não seguem rigorosamente suas próprias regras. Vamos aprofundar sobre isso tomando o caso em que a realidade é fiel ao modelo na proporção de, digamos, $20 \%$ dos casos. Por exemplo, é isso que acontece nas sociedades que prescrevem casamento entre primos cruzados, mas onde, na verdade, apenas cerca de $15 \%$ ou $20 \%$ dos casamentos ocorrem dessa forma. Nesses casos, não podemos dizer que o modelo não está 
em conformidade com a realidade, pois sabemos que por muitas razões - históricas, demográficas e outras - seria impossível praticar casamento entre primos cruzados numa taxa mais alta. E, mesmo em um caso como esse, eu mantenho que uma taxa de $20 \%$ no casamento entre primos cruzados é ampla o suficiente para caracterizar a sociedade com uma dada estrutura, para dar uma forma definida ao que podemos chamar de espaço genealógico, para fazer dessa sociedade um membro de uma sorte de espécie dentro da taxonomia de grupos humanos. Não deveria ser descartado como um caso em que modelo e realidade não correspondem estreitamente um ao outro.

A outra questão, feita adequadamente por Schneider, é que um modelo não é algo diferente da realidade; antes, um modelo tem uma realidade própria. Um modelo pode ser diferente do que acontece no campo, mas é real, no entanto, e deve ser estudado como perfeitamente objetivo. Eu acredito que as razões para estas dúvidas acerca da realidade dos modelos têm a ver com a suposição de que todos os modelos existem apenas como construtos na mente do antropólogo. No entanto, pode ser demonstrado que frequentemente modelos existem na mente do nativo e que, possivelmente, eles são algo mais: talvez eles sejam os produtos remotos de uma antiga tradição que se perpetua na sociedade estudada.
Temos tentado comparar os dados da antropologia social com os da pré-história. Mas vale a pena perguntar-se sobre as ideias que os próprios caçadores-coletores têm sobre a préhistória. Nos meus estudos de mitologia, me deparei com algumas concepções muito marcantes na mente de certas tribos sul-americanas. Pode ser mostrado como na mitologia está embutida, por assim dizer, uma teoria do parentesco. Deixem-me rapidamente dar um exemplo. Na América do Sul, os mitos que lidam com a origem da cultura (isto é, a invenção do fogo, o cozimento da carne e os primeiros utensílios) convocam protagonistas que geralmente têm relações muito precisas entre si. Eles são afins e, além disso, afins de uma forma muito especial - seja o irmão da irmã, o irmão da esposa ou o marido da irmã. Estes também são os tipos de afins que nos sentimos obrigados a representar em nossos diagramas, pois eles são necessários para expressar a parte masculina e feminina de uma linhagem; eles são os homens que trocam mulheres entre si. Os mitos sulamericanos que lidam com a origem do cultivo, no entanto, trazem em cena afins de um tipo diferente - tais como a irmã da esposa e o irmão do marido -, sendo estes os tipos de pessoas que desconsideramos em virtude do princípio de equivalência de irmãos, bem conhecido na teoria do parentesco desde Radcliffe-Brown. Portanto, 
nesses mitos temos dois modelos diferentes de relações de parentesco: o primeiro, que poderia ser chamado de modelo "paleolítico" (sem implicar qualquer conotação histórica), mostra a redução a elementos básicos e indispensáveis, de forma que as trocas matrimoniais possam ocorrer. No segundo, ou modelo "neolítico" (já que se encontra nas referências às origens do cultivo), a composição da família torna-se aleatória, e há muitas pessoas para cumprir perfeitamente os requisitos da troca; aparecem afins supranumerários que são inúteis na estrutura social, com uma função social geralmente limitada à de potencial sedutor do cônjuge do irmão/irmã. Aqui podemos ver que a distinção entre o que podemos chamar de afins paralelos e de afins cruzados não está apenas na mente do antropólogo, mas profundamente enraizada nos princípios dos mitos.

Hiatt sugeriu duas explicações possíveis para a discrepância entre modelo e realidade na sociedade australiana; no entanto, há também uma terceira que vale a pena considerar - que, em seu momento, esta teoria completa foi claramente concebida e inventada por sociólogos ou filósofos nativos. Assim, o que estamos fazendo não é construir uma teoria com a qual interpretar os fatos, mas sim tentar retornar à mais antiga teoria nativa na origem dos fatos que estamos tentando explicar. Afinal, sabemos que a humanidade tem cerca de um ou dois milhões de anos, mas, ao mesmo tempo que estamos prontos para conceder ao homem esta grande antiguidade, não estamos prontos para conceder-lhe uma contínua capacidade de pensar durante esse enorme período. Não vejo razão para que a humanidade espere até tempos recentes para produzir mentes do calibre de um Platão ou um Einstein. Já mais de duzentos ou trezentos mil anos atrás, provavelmente havia homens com capacidade semelhante, que obviamente não estavam aplicando sua inteligência para a solução dos mesmos problemas que esses pensadores mais recentes; em vez disso, eles estavam provavelmente mais interessados em parentesco!

O terceiro nível de ambiguidade penetrou em nossas discussões inesperadamente graças aos nossos colegas australianos, que começaram a questionar velhos resultados sobre coisas que infelizmente não existem mais. A grande questão que é assim levantada refere-se à natureza da verdade na pesquisa antropológica. Quando nos dizem que os fatos de cinquenta anos atrás (que não podem ser reestudados) não são exatamente tal como o observador atual os descreve, somos levados a nos perguntar se são os objetos antropológicos que mudaram ou se é a própria antropologia que mudou e, portanto, não pode mais satisfazer a si própria com os mesmos tipos de respostas. O que é realmente "verdade" na antropologia? O que é 
realmente "provado"? A verdade antropológica possui evidência factual do mesmo tipo que a procurada pelas ciências exatas, ou ela consiste em um tipo especial de relação entre o observado e o observador? Como com o estudo daqueles objetos que são tão distantes (seja porque eles estão longe ou porque existem numa escala tão pequena que nunca apreenderemos como eles são de fato), nossa percepção das entidades antropológicas estará limitada pelas diferentes maneiras em que as percebemos. E, nesse caso, a única pretensão de verdade que podemos ter será limitada a um conjunto de pontos de vista complementares que deixam espaço para incertezas fundamentais, incapazes de resolução final. Assim, não se pode dizer que um tipo de explicação deve ou irá suplantar outro tipo. Em vez disso, um fato que deve para sempre permanecer desconhecido será cada vez mais cercado por diferentes perspectivas, mas estas serão perspectivas sobre uma coisa que por si permanecerá inatingível. Isso tem a ver parcialmente com o assunto em questão: o observador nunca pode coincidir com o observado e, apesar do fato de que nas ciências humanas o que é observado e quem observa pertencem à mesma categoria de coisas, eles nunca podem tornar-se o mesmo indivíduo sem perder a abordagem e a perspectiva científica. Parece-me que, de um ponto de vista epistemológico, o que aprendemos sobre a evolução da concepção de bando ou horda australiana levanta uma questão extremamente importante, não apenas para os estudos antropológicos australianos, mas para os problemas fundamentais que enfrentamos.

Se me permitem tirar uma conclusão a partir dessas observações, provavelmente deveríamos ser mais cautelosos ao tentar descartar o trabalho de nossos grandes antecessores à luz de novas abordagens ou observações recentes. O que eles viram e registraram já passou, e não podemos ter certeza de que estamos, de fato, observando o mesmo tipo de evidência. Na antropologia, como em outros lugares, o progresso nunca resultará da destruição do que foi anteriormente alcançado, e sim da incorporação do passado da nossa ciência no presente e no futuro, enriquecendo um com o outro e transformando todo o processo em uma realidade duradoura.

\section{REFERÊNCIA}

Lévi-Strauss, C. 1963. The concept of archaism in Anthropology, in Structural Anthropology, pp. 101129. New York: Basic Books. 